NBER WORKING PAPER SERIES

THE STOCK MARKET, PROFIT AND INVESTMENT

\author{
Olivier Blanchard \\ Changyong Rhee \\ Lawrence Summers
}

\author{
Working Paper No. 3370 \\ NATIONAL BUREAU OF ECONOMIC RESEARCH \\ 1050 Massachusetts Avenue \\ Cambridge, MA 02138 \\ May 1990
}

We thank the NSF for financial support, Robert Barro, Ben Bernanke, Peter Boone, Yeeyoung Song and Lawrence Katz for useful discussions. This paper is part of NBER's research program in Financial Markets and Monetary Economics. Any opinions expressed are those of the authors and not those of the National Bureau of Economic Research. 
Working Paper \#3370

May 1990

THE STOCK MARKET, PROFIT AND INVESTMENT

ABSTRACT

Should managers, when making investment decisions, follow the signals given by the stock market even if those do not coincide with their own assessments of fundamental value? This paper reviews the theoretical arguments and examines the empirical evidence, constructing and using a new US time series of data on the $q$ ratio from 1900 to 1988. We decompose $q$-- the ratio of the market value of corporate capital to its replacement cost - - into the product of two terms, reflecting "fundamentals" and "valuation", the ratio of market value to fundamentals. We then examine the relation of investment to each of the two, using a number of alternative proxies for fundamentals. We interpret our results as pointing, strongly but not overwhelmingly, to a larger role of "fundamentals" than of "valuation" in investment decisions.

Olivier Blanchard

MIT

Department of Economics

50 Memorial Drive

Cambridge, MA 02139
Changyong Rhee

University of Rochester

Department of Economics

Rochester, NY 14627
Lawrence Summers

Harvard University

Department of Economics

Littauer 229

Cambridge, MA 02138 
In recent years economists have started to take seriously the idea that the stock market does not always provide the best available estimate of fundamental value. Theoretical and empirical studies along with the Crash of 1987 have led to an upsurge of interest in theories of market fluctuations that emphasize the role of poorly informed traders or bubbles. If market movements do not all reflect changes in fundamental value, it is natural to ask whether the economic response to market movements will differ depending on their cause. This question takes on particular importance in light of the failure of the collapse of investment, widely predicted after the 1987 Crash, to materialize. This paper tries to sort out the theoretical and empirical evidence on whether and how investment responds to changes in fundamentals and in market value.

In Section $I$, we take up the following question. Should managers, in making investment decisions, follow --always, sometimes, never-- the signals given by the stock market, or more precisely by $q$, the valuation of their capital by the asset markets, even if their own valuation of those investment projects does not coincide with the stock market's valuation? This question takes on considerable importance given that there is considerable evidence suggesting that stock prices may often deviate from fundamental values. Bosworth (1975) argued that firms should disregard the market when they think it is wrong. Fischer and Merton (1984) in contrast argued that firms should respond to the market valuation, even if they do not agree with it. We reexamine the question and conclude that neither extreme theoretical view gives correct guidance to managers. Furthermore, 
actual managerial behavior is an empirical question. We therefore turn to the data.

In Section II, we describe the data and layout our basic empirical approach. We look at data for the US from 1900 to 1988; one of the contributions of this paper is to construct a series for $q$ for that period. Our basic strategy is then to think of $q$ as the product of two terms, "fundamentals" - the expected present discounted value of profits- and "valuation" - the ratio of the market value to fundamentals-, and to see whether investment responds equally to both. If fundamentals were observable, then testing whether investment is driven by market or managerial perceptions would be straightforward: the first implies that only fundamentals should matter, while the second implies that both terms matter equally. The obvious problem is that fundamentals are not observable, and one must rely on proxies. We explore two different approaches.

The first, developed in Sections III to $v$, relies on the use of proxies for fundamentals in the investment equation. In Section III, we use current dividends as a proxy for fundamentals. The rationale for using dividends traces back to the work of Lintner (1956), and is based on the idea that managers set dividends in line with their perceptions of permanent earnings. In Section IV, we construct a series for the expected present discounted value of profits under the assumption of rational expectations; we do so by constructing the realized present discounted value of profits and by projecting it on a set of instruments. Under both approaches, the evidence is that firms react to both components of $q$, to 
fundamentals as well as to valuation, the ratio of market value to fundamentals. Point estimates imply a stronger effect of fundamentals; the difference is not however statistically significant.

Both sets of results are however likely to suffer from a systematic bias in the coefficients. The use of a proxy for fundamentals implies that some information about fundamentals will be contained in the term we use to measure valuation - the ratio of market value to our proxy for fundamentals. Intuition suggests that this will lead to an underestimate of the difference between the effects of fundamentals and valuation. In section $v$, we formalize this intuition and characterize the size of the bias in that difference as a function of how much information about fundamentals is actually contained in the term we construct to measure valuation. We conclude that under plausible assumptions, the bias may be substantial. If so, our empirical results can be interpreted as suggesting a substantially and significantly stronger effect of fundamentals than valuation on investment.

Our second approach, developed in Section VI, looks instead at two specific episodes, the periods around the market crashes of 1929 and of 1987. It relies on the idea that, during those episodes, there was widespread suspicion that the market value diverged from fundamentals. Thus, if investment decisions depend mostly on fundamentals, one would expect the relation between investment and market value to be weaker during those periods. If instead investment decisions depend equally on fundamentals and valuation, these episodes should not look abnormal. Examination of the two episodes yields different conclusions. The 1929 
period just does not fit any simple hypothesis. The 1987 experience is consistent with the idea that firms ignored valuation and followed

fundamentals. This finding in turn explains why the crash of 1987 was not followed by a substantial fall in investment. 


\section{Section I. The stock market and investment}

Should we expect a tight relation between investment and the stock market? It is useful to start with an admittedly irrelevant but simple benchmark case. Suppose that the profit function were linear in capital, that firms had stable adjustment cost functions for capital, that managers and asset market participants had access to the same information set and that asset markets valued firms at their fundamental value. Then, it is well known, from Hayashi (1982), that the ratio of investment to capital .. investment for short-- and the ratio of the market value of the firm to the replacement cost of capital -.q for short-. would move together, both responding in the same way to expectations of profits and required rates of return. $q$ would not cause investment in any useful sense, although managers would probably find it convenient to rely in part on the valuation performed in asset markets.

A more interesting question arises when we allow for the possibility that the valuation of investment projects by the managers of firms and the market valuation of existing capital do not coincide. There is one well known reason why this might be so, which is referred to in the literature as the difference between marginal $q$, the shadow value of additional capital, and average $q$, the value of existing capital. The two will be different whenever marginal profit and average profit are different; the classic example is an energy price shock that renders old capital unprofitable to operate but encourages energy conserving investment. Other cases include non constant returns in production, rents to non 
reproducible factors, rents in non competitive goods or factor markets, or features of the $\operatorname{tax}$ system $^{1}$. In our discussion, we leave this issue aside, implicitly assuming marginal and average profit to be the same, in order to focus on the issue we are concerned with, namely differences in the valuation of a given investment project by managers and the market.

We thus rephrase our question as: what should managers do if their valuation of an investment project differs from that of the market? There are three reasons why this may be so, and all three have been examined at length in the recent literature. First, the market may have less information than managers. Second, even if information sets are the same, the market may not value assets at their fundamental value, and market valuation includes a rational speculative bubble. Prices are high relative to fundamentals simply because they are expected to increase, or low simply because they are expected to decrease (Blanchard and Watson 1982). Third, the market may be subject to fads which cause market valuation to deviate from fundamentals for long periods of time. Although the expected excess return from buy low-sell high strategies is positive, it is sufficiently small and the risk sufficiently large that the market does not eliminate the deviation (DeLong, Shleifer, Summers, and Waldman (1987)). Suppose that for any of these reasons, the market value deviates from the managers' evaluation of fundamentals. What should a manager then do? Should it react differently depending on why the two differ?

1 See Hayashi (1982), Abel and Blanchard (1986). 
A first answer to that question was given by Bosworth (1975), who argued that managers should simply ignore the sideshow provided by the stock market and act upon fundamentals as they perceived it. To discuss his and other arguments, it will be convenient to rely on the special case of risk neutrality and no costs of adjustment. For that case, define $q$ as the ratio of the market valuation to the replacement cost of capital, and $q_{m}$ ( $m$ for managers) as the present discounted value of marginal profits, as assessed by managers, discounted at the riskless rate. In that case, Bosworth argues, managers should invest to the point where the marginal product is equal to the riskless rate, or equivalently where $q_{m}=1$, whether or not at that point this is also true of $q$, the stock market valuation.

The argument would be correct if the stock market was indeed purely a sideshow--that is if its only function was to value existing projects and if existing shareowners never sold their shares.. In this case, the firm would finance itself by borrowing at the riskless rate and it would be acting in the interests of its owners by ignoring the stock market's assessment But the stock market is also a market where firms can issue new shares and where existing sharehowners can realize capital gains by selling to potential buyers; the price that the market puts on these shares is therefore relevant for investment decisions. The possibility of new share issues was emphasized by Keynes (1936, p151), and was the initial motivation given by Tobin for the $q$ theory. It underlies the second answer 
to the investment-stock market relation, an answer articulated by Fischer and Merton (1984). Fischer and Merton argued that investment decisions should be based on the stock market valuation. Their argument is simple: if the market is ready to accept a lower rate of return, the firm should then invest until the marginal product of capital is equal to that rate of return. In the case introduced above, assume that investment has proceeded to the point where $q_{m}$ is equal to 1 . If, at that point, $q$ exceeds 1 and the market is ready to pay more than 1 for a share, the firm should issue new shares and invest until $q$ itself has been driven down to 1 . At that point $q_{m}$, as assessed by managers, will be less than 1, reflecting the decrease in the marginal product of capital. But existing shareholders will have made a profit on each new share which has been issued. Driving investment to the point where the market valuation of capital is equal to its replacement cost maximizes the wealth of existing shareholders. Thus, Fischer and Merton argue, investment should respond to stock market movements, whether or not these movements reflect managers' assessments of fundamentals. This however is not the end of the story, and there are at least three reasons why the Fischer-Merton argument is incomplete.

First, within the logic of the argument, the best strategy for the firm is indeed to issue new shares, but to use the proceeds not for physical investment, but for lending at the riskless rate, for example to buy Treasury Bills. This is because investing in additional capital drives down its marginal product below the riskless rate, while lending at the riskless rate is equivalent to investing in a constant returns technology. Indeed, pushing this argument to its logical conclusion, the optimal 
strategy if $q$ exceeds $q_{m}$ must be to issue an infinite amount of shares and invest the proceeds in the riskless asset... But this leads to the second argument.

The difference between $q$ and $q_{m}$ is unlikely to be invariant to the actions of the firm, for example, the issue of new shares and the decision whether to use the proceeds to buy Treasury bills or for physical investment. Here, knowing why $q$ and $q_{m}$ differ is important. If the difference comes from differences in information, one would expect issues of new shares and the use of the proceeds to play the role of signals, and to affect the market valuation. If the difference comes from speculative bubbles or fads, we have no theoretical guidance as to what the action of the firm may do to the difference between $q$ and $q_{m}$. Seeing a firm issue new shares and use the proceeds to invest in outside opportunities might well prick a bubble. Put another way, the bubble may be on the capital of the firm than on the firm itself. For all those reasons, a firm may be reluctant to change its investment plans to take account of what it perceives as erratic differences between $q$ and $q_{m}{ }^{2}$.

Third, while the current shareholders benefit from the issuance of new shares, it is clear that the issue of new shares by itself represents a pure transfer. From whom the transfer comes depends again on why $q$ and $q_{m}$ differ. In the case of better information on the part of managers or in the case of fads, the transfer is from the new shareholders to the existing

2 This paragraph summarizes the essential conclusion of a large literature on the adverse signalling effects of new equity issues. See for example Myers and Majluf (1984). 
ones. In the case of rational bubbles, the transfer is from future buyers of the shares to existing shareholders: new shareholders are not worse off in expected value, as they rationally expect to recover the high purchase price by selling at an even higher price to others in the future. In addition, in the case of fads, if the money from new share issues is used for physical investment driving the marginal product down, the set of existing and new shareholders as a whole is unambiguously worse off as a result. Thus, the managers, who will in time be responsible to the new as well as the old shareholders may be reluctant to engage in such behavior. While our discussion of the Fischer-Merton argument has proceeded under the assumption that firms were issuing new shares, similar issues arise even when issuing or repurchasing shares is not an option. In that case, current shareholders will realize their gains only if and when they sell their own shares. Thus, what managers should do will depend both on their perceptions of how long they expect market value to deviate from fundamentals, and on how long they expect their shareholders to hold on to their shares. Put another way, managers who are primarily concerned with their long term shareholders should follow their own judgements rather than the market's judgement in evaluating investment projects. But managers of firms whose shareholders have short horizons should follow Fischer and Merton and invest in relation to market valuation. They may indeed have a strong incentive to do so to the extent that managerial compensation (broadly defined) is tied in part to the market's judgement of their performance. 
Thus, when all is said and done, theory does not provide an unambiguous answer as to whether firms should invest be based on market or managerial perceptions. We therefore turn to the data.

\section{Section II. Methodology and data}

The investment equation.

We introduced a simple benchmark at the beginning of the previous section. We assumed that marginal and average profit were equal, that managers and the market had similar information sets, and that there was no arbitrage failure and no bubbles. Under that benchmark, investment depended on the expected present discounted value of profits accruing to an additional unit of capital. The equality of marginal and average profit implied in turn that this expected present discounted value of marginal profits was equal to $(F / K)$, where $F$, "fundamentals", was the expected present discounted value of profits accruing to current capital. Finally, our assumptions about asset markets implied that $(F / K)$ would also be equal to $(V / K)$, where $V$ was the market value of current capital.

While maintaining the assumptions that marginal and average profit were equal, we then allowed for either different information sets, or failures of arbitrage, or bubbles. There was then no longer any reason to expect $(F / K)$, the managers' perception of the present discounted value of future profits to equal $(V / K)$, the market valuation, and the question became that of whether managers would respond to $(F / K)$ or $/$ and to $(V / K)$. 
This motivates our basic approach to the investment equation. Note that $q$ can be written as the product of the two terms, $(F / K)$, "fundamentals", and $(V / F)$, "valuation", the ratio of market value to fundamentals:

(1) $q-(V / K)-(F / K)(V / F)$

This in turn suggests the following specification of the investment equation, which allows both components of $q$ to enter separately:

(2) $\ln (I / K)-c+a(L) \ln (F / K)+b(L) \ln (V / F)+\epsilon$

Suppose that fundamentals, $F$, were observable. Then estimation of (2) would be straightforward. The managerial perceptions hypothesis that firms respond only to fundamentals as they perceive them would correspond to $b(L)-0$. The alternative market perception hypothesis that firms respond to movements in $q$ no matter their source would correspond to $a(L)=b(L)$; $a$ weaker form of the hypothesis might be $a(1)-b(1)$, that the sum of coefficients on the fundamental and the valuation terms were equal.

The obvious problem is that $F$ is not observable. This leads us to follow two complementary approaches. The first is to use an observable proxy for $F$ and estimate equation (2). In Section III, we assume that $F$ is simply proportional to dividends, $D$. In section IV, we construct $F$ as the projection of the ex post present discounted value of profits on information available as of the time of the investment decision. The use of a proxy for fundamentals leads however to a systematic bias in the coefficients. The nature of the bias as well as its potential size are the subject of Section $v$. Our second approach focuses instead on specific episodes. It is based on the idea that, at a few times in the past, 1929 , 
1987, there has been widespread suspicion of deviations of the market value from fundamentals; we therefore regress investment on $q$, thus forcing the coefficients on valuation and fundamentals to be same, and examine the residuals of the equation during those episodes.

The data

We decided that the best data set for our purposes would be a long data set, in which we could characterize the basic relation of investment to $q$, profit, dividends and capital. Therefore we focused on annual data for the US since $1900^{3}$. This implied the construction of a $q$ series for the period 1900 to 1958 (as a q series already exists post 1958). The details of construction, as well as the q series for 1900-1988, are given in appendix 1. The appendix also gives sources for the other series used in estimation. Series for profit are only available since 1916; all other series are available from 1900 on. In all cases, we have tried to construct variables which correspond to the private non financial corporate sector of the economy.

The basic time series are plotted in three sets of figures. Figure la plots the ratio of investment to capital, ( $I / K)$, against $q$, the market

3 We have also looked at the period 1952-1988 for which quarterly data exist and thus quarterly regressions can be run. Another advantage of looking at postwar data is that the information needed to go from the differences between marginal and average $q$ due to the tax system is available. Because those data have already been examined at length by other researchers, we do not report the results here. The results are in general very similar to those reported in the text for the postwar sample, using annual data and no tax correction. 


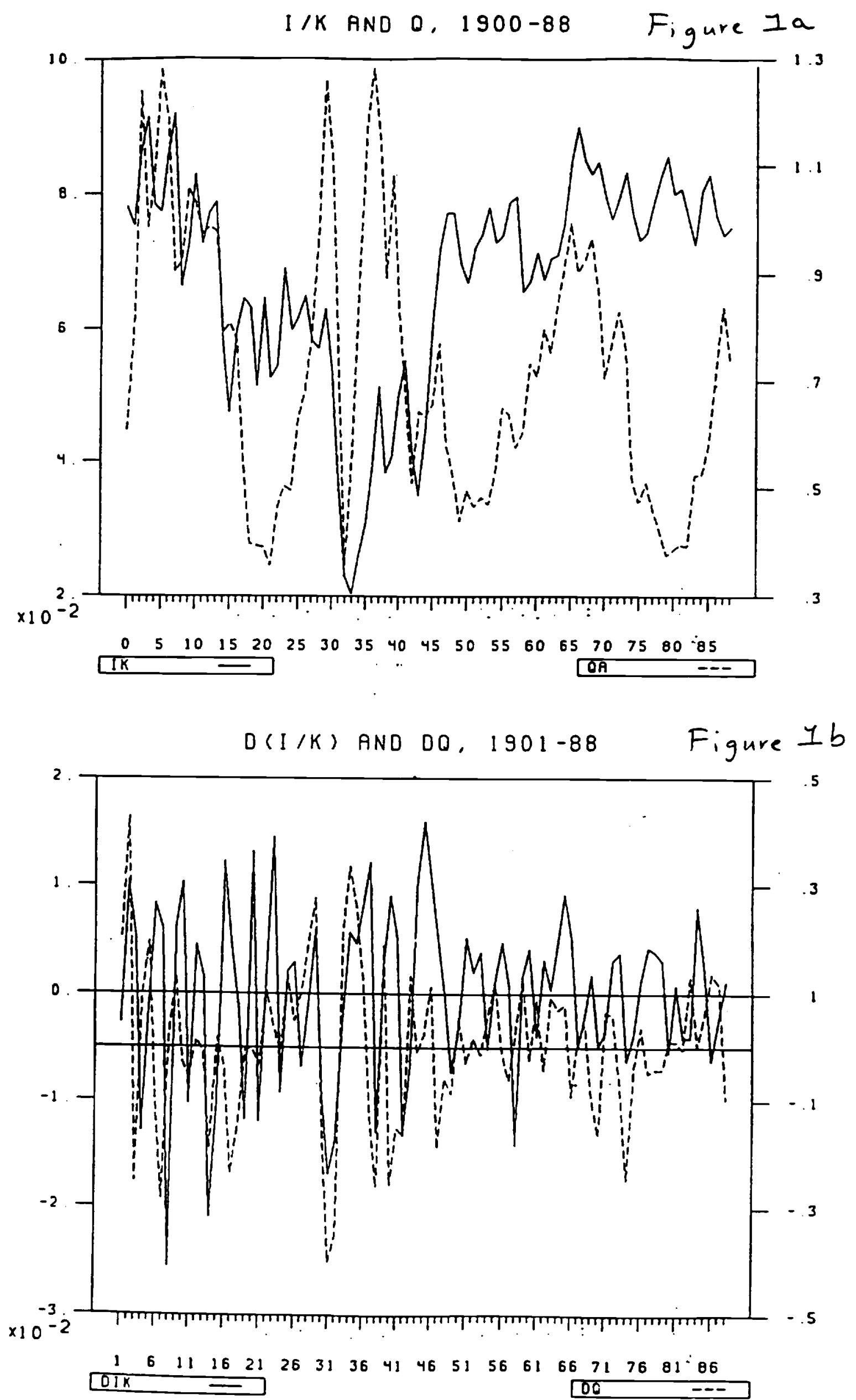


I/K ANO OIVIDEND/K, 1900-88 Figure $2 a$

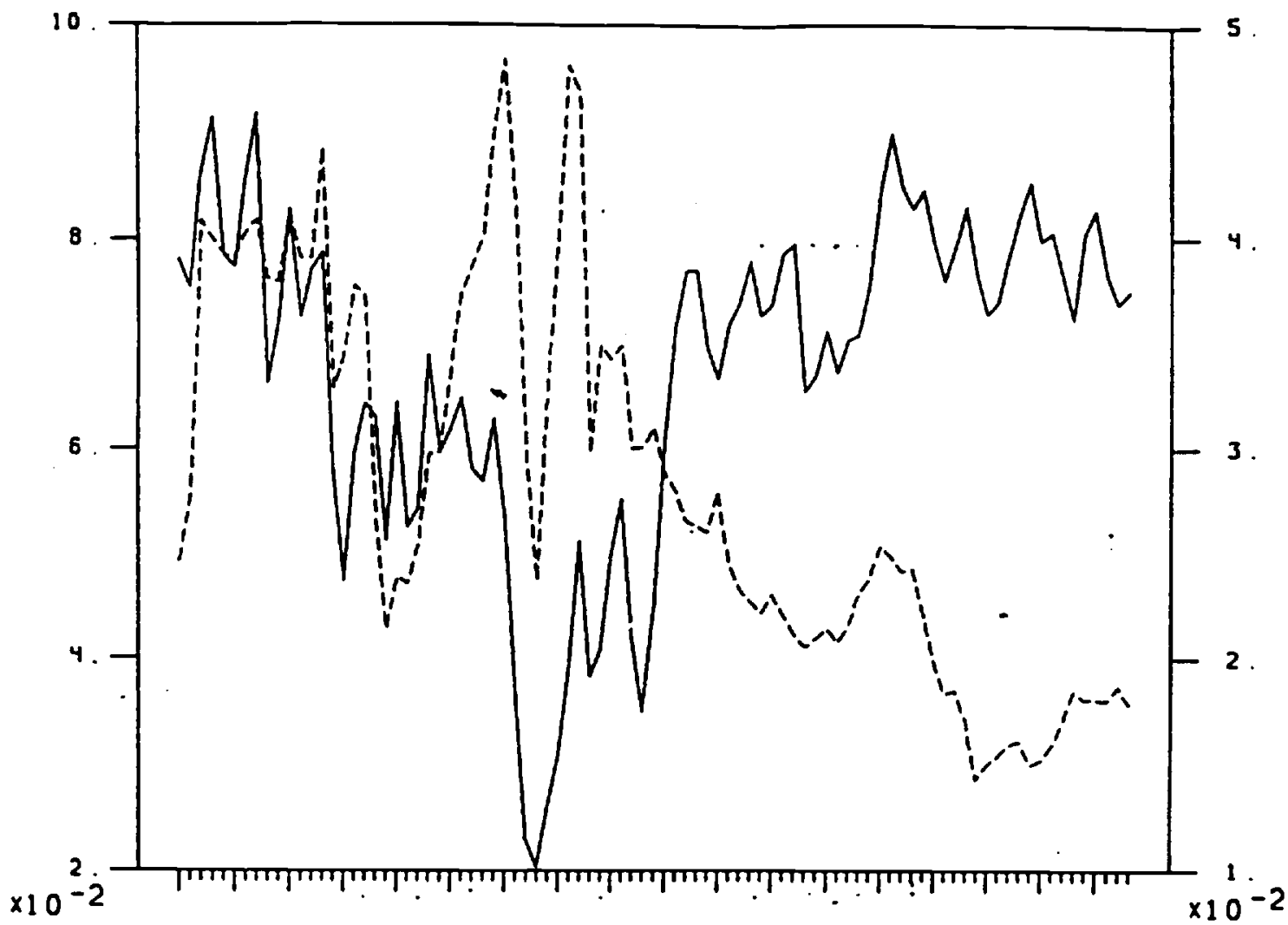
\begin{tabular}{|llllllllllllllllll}
0 & 5 & 10 & 15 & 20 & 25 & 30 & 35 & 40 & 45 & 50 & 55 & 60 & 65 & 70 & 75 & 80 & 85 \\
\hline$I K$ & & & &
\end{tabular}

$D(I / K)$ AND O(OIVIOEND/K), 1901-88 Figure 2 b

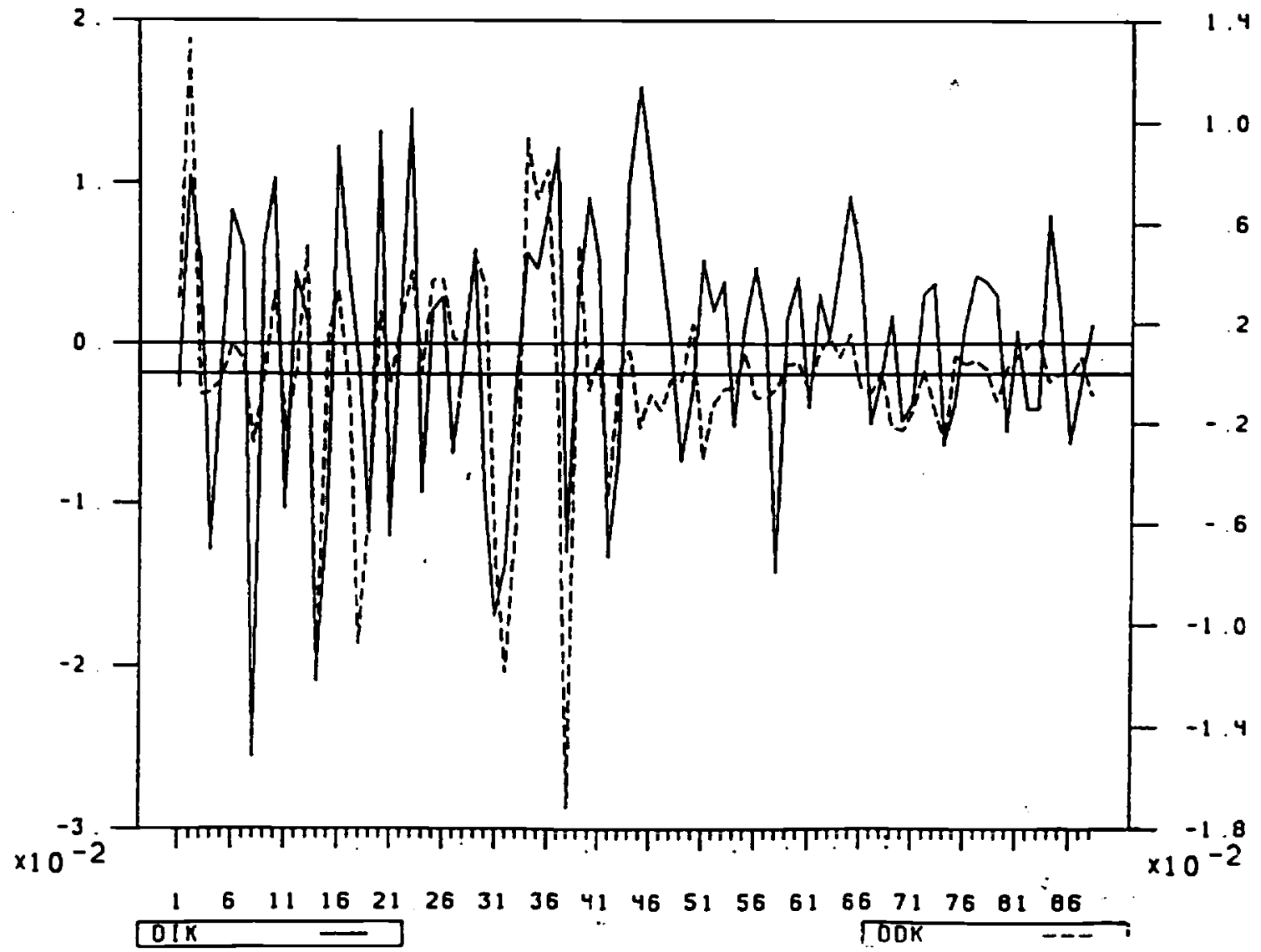


$1 / K$ AND PROFIT/K, 1916-88 Figure $3 a$

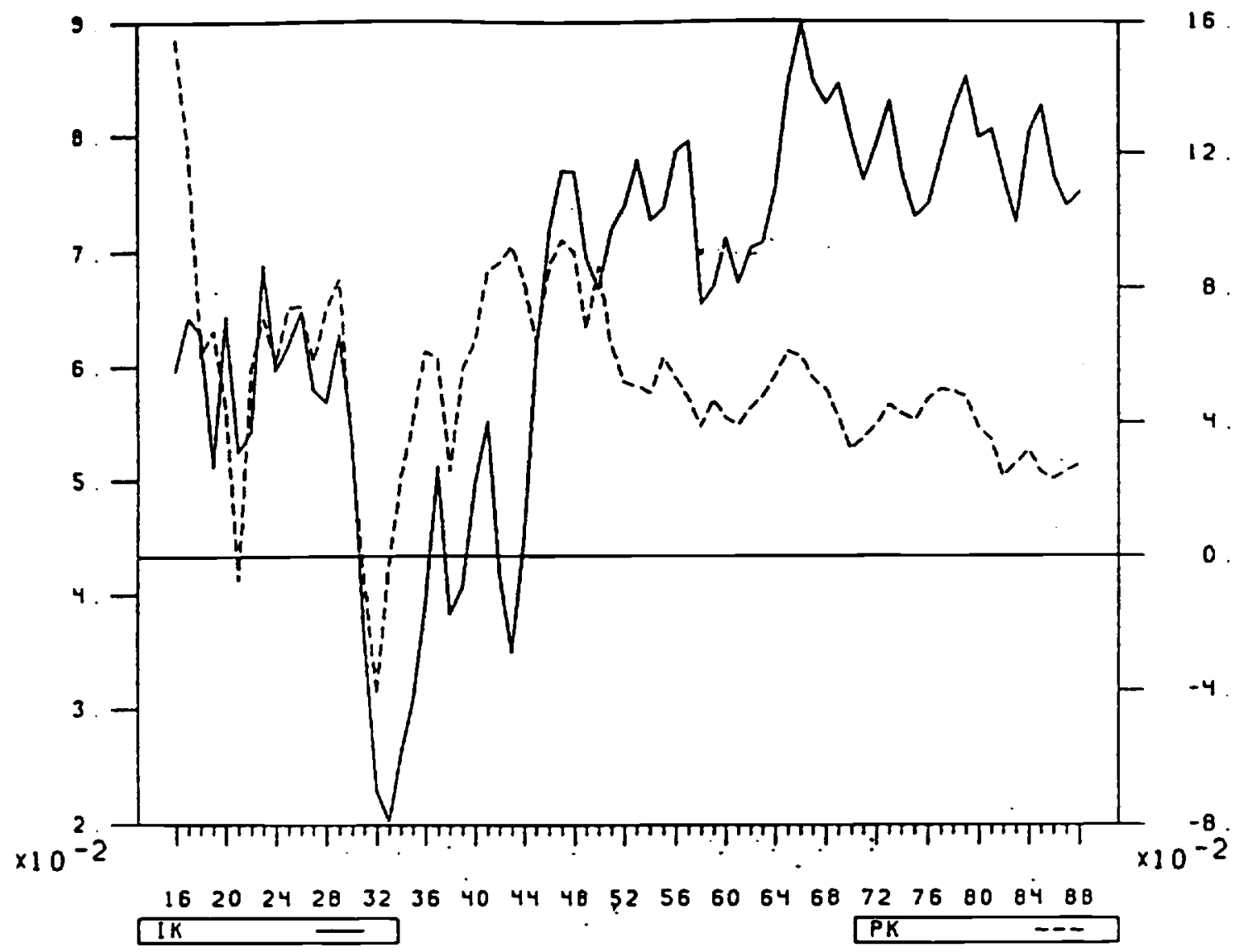

$D(I / K)$ AND $D(P R D F I T / K), 1917-88$ Figure $3 b$

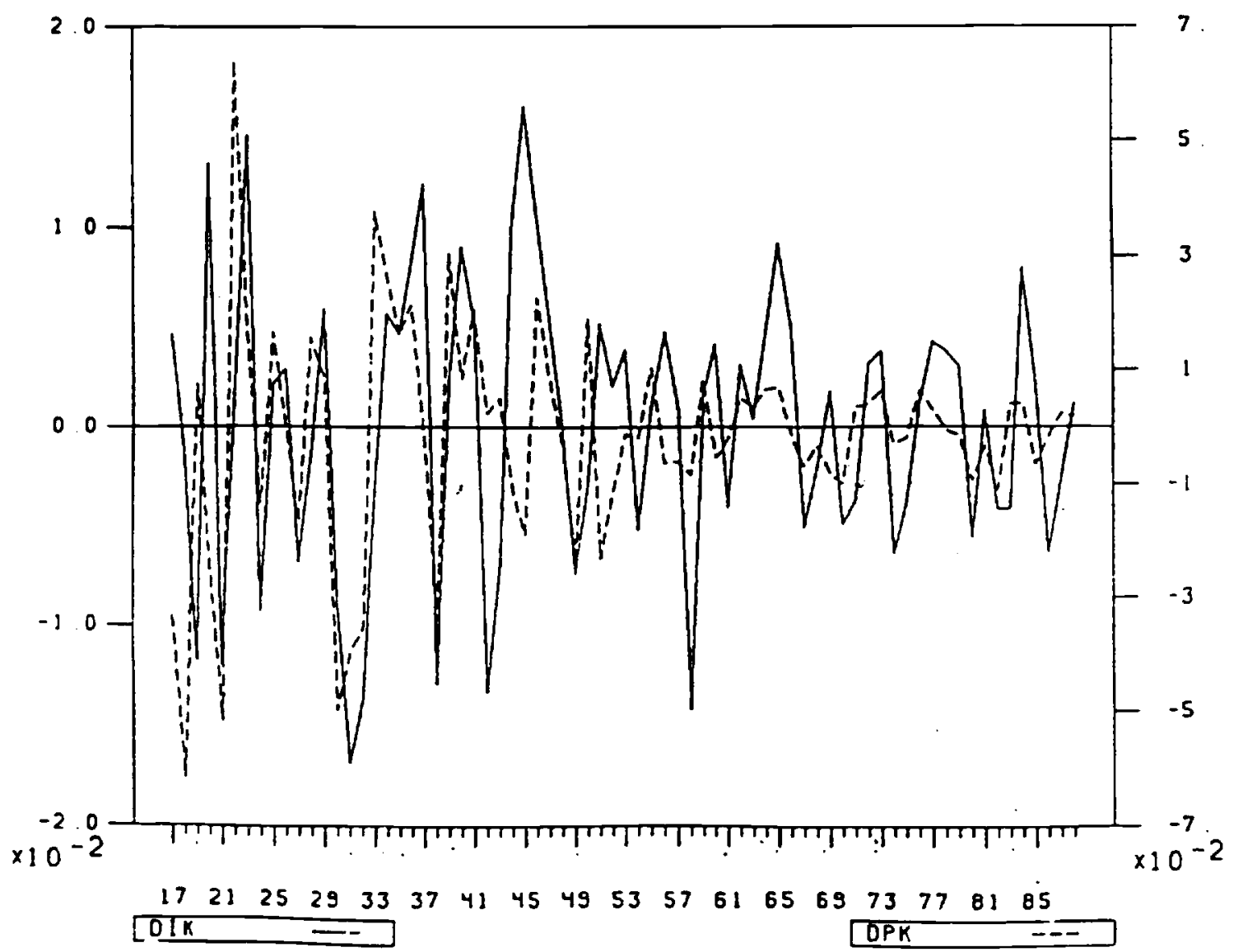


value of capital divided by replacement cost. Figure lb does the same for first differences of $(I / K)$ and $q$. Figure $2 a$ plots $(I / K)$, this time against the ratio of dividends to capital, $(D / K)$ and figure $2 b$ plots first differences. Finally figure $3 a$ plots $(I / K)$ against the ratio of after tax profits to capital, $(\pi / K)$, and figure $3 b$ plots first differences; because profit series are not avallable pre 1916, figure 3 covers only 1916-1988.

Three characteristics emerge from these figures.

First, the series for $q$ confirms the picture of $q$ given by postwar data (see for example Summers 1981). Just as there is the puzzle of why $q$ was so low (absolutely, and in relation to investment) in the $1970^{\prime}$ s, there is the puzzle of why q was so low in the $10^{\prime} \mathrm{s}$ and $20^{\prime} \mathrm{s}$. The crash of 1929 and its after-effects are clearly visible: q decreases sharply from a high of 1.25 in 1929 to a low of .35 in 1932. But perhaps the most surprising feature of the $q$ series is its sharp rebound from 1932 to 1936, so that by 1936. q stands at its highest value for the period 1900-1988. This comes from both a sharp increase in the stock market and -in contrast to other sharp movements in $q$ over the period-a sharp decrease in the nominal value of the capital stock. The Cowles Commission index of stock price increases from 48 in 1932 to 111 in 1936. With gross investment being close to zero from 1930 to 1933, the capital stock of the non financial corporate sector decreases from 121 billion dollars in 1929 to 95 billion dollars in 1936.

There is a clear relation between $(I / K)$ and either $q,(D / K)$ or $(\pi / K)$. But the relation is a not a tight one, especially at low frequencies. For example, a given value of $(I / K)$ is associated with a lower value of $q$ in the postwar period. $(D / K)$ and $(\pi / K)$ both exhibit postwar downward trends 
which are not reflected in $(I / K)$. The plots of first differences show that, in all three cases, the relation is stronger at high frequencies. It is not obvious from those graphs of first differences that $(I / K)$ is more strongly related to either $q,(D / K)$ or $(\pi / K)$. The heteroskedasticity in all four time series, with much smaller movements in the postwar period, also makes the task of visually assessing fit difficult. Thus, as a way of further describing the data, table 1 reports the results of simple horse races.

In each case, regressions are run in first differences, with $\Delta(I / K)$ as the dependent variable and a constant term and a distributed lag of either $\Delta q, \Delta(D / K), \Delta(\pi / K)$ as regressors ${ }^{4}$. We use first differences as estimation in levels with first order serial correlation yielded estimates of the degree of first order serial correlation insignificantly different from one. In each case, the regression is estimated over the period 1900-1939, 1948-1988 (or 1916-1939,1948-1988 when profit is used), and over each of the two subsamples separately. Leaving WWI years in -or leaving WWI years out-makes little difference to the estimates. In each case one lag on the independent variables is sufficient, and the lagged first difference of investment is insignificant if included. The table makes two points:

4 These are first differences of levels, not of logarithms. The reason is that profit is negative for a few years in the sample. Thus, we must use the level of profit, and to allow for comparison of fits, use levels of the other variables as well. Doing the regressions which include either $D / K$ or $q$ in logarithms yields results similar to those in table 1. 
Table 1. Investment, $q$, dividends and profits

Dependent variable : $\Delta(I / K)$

\begin{tabular}{|c|c|c|c|c|c|}
\hline Sample & $\Delta q$ & $\Delta q(-1)$ & DW & $\mathrm{R}^{2}$ & $\begin{array}{l}\text { Chow test } \\
\text { (SF level) }\end{array}$ \\
\hline Full & $\begin{array}{l}0.007 \\
(1.4)\end{array}$ & $\begin{array}{l}0.026 \\
(4.9)\end{array}$ & 2.22 & .27 & \multirow{3}{*}{.56} \\
\hline Prewar & $\begin{array}{l}0.011 \\
(1.4)\end{array}$ & $\begin{array}{l}0.025 \\
(3.2)\end{array}$ & 2.34 & .27 & \\
\hline \multirow[t]{2}{*}{ Postwar } & $\begin{array}{l}-0.006 \\
(-0.8)\end{array}$ & $\begin{array}{l}0.030 \\
(3.9)\end{array}$ & 1.83 & .26 & \\
\hline & $\Delta(D)$ & 2) $\Delta(D / K)(-1)$ & DW & $\mathrm{R}^{2}$ & \multirow{4}{*}{.22} \\
\hline Full & $\begin{array}{c}0.98 \\
(5.5)\end{array}$ & $\begin{array}{c}0.13 \\
(0.7)\end{array}$ & 2.20 & .28 & \\
\hline Prewar & $\begin{array}{l}1.03 \\
(4.5)\end{array}$ & $\begin{array}{r}0.07 \\
(0.3)\end{array}$ & 2.33 & .34 & \\
\hline \multirow[t]{2}{*}{ Postwar } & $\begin{array}{l}-0.02 \\
(0.0)\end{array}$ & $\begin{array}{l}1.62 \\
(2.7)\end{array}$ & 2.04 & .12 & \\
\hline & $\Delta(\mathbb{I I})$ & $\Delta(\mathbb{I} / \mathrm{K})(-1)$ & $\mathrm{DW}$ & $R^{2}$ & \multirow{4}{*}{.67} \\
\hline Full & $\begin{array}{r}0.13 \\
(4.5)\end{array}$ & $\begin{array}{l}0.18 \\
(5.7)\end{array}$ & 2.09 & .46 & \\
\hline Prewar & $\begin{array}{l}0.13 \\
(3.1)\end{array}$ & $\begin{array}{r}0.16 \\
(3.9)\end{array}$ & 2.25 & .55 & \\
\hline Postwar & $\begin{array}{r}0.21 \\
(2.5)\end{array}$ & $\begin{array}{r}0.28 \\
(3.5)\end{array}$ & 1.87 & .25 & \\
\hline
\end{tabular}

Full sample : 1902-1939, 1948-1988 (1918-1939, 1948-1988 for profit regressions); Prewar : 1902-1939 (1918-1939 for profit regressions); Postwar : 1948-1988. t statistics in parentheses 
All three independent variables are significant. The horse races are close : the $R^{2}$ 's of the regressions are similar for $q$ and for dividends, and somewhat higher for profit.

The lag structures are sometimes different across subsamples. Lagged dividends are highly significant prewar, current dividends highly significant postwar. But in no case is there any statistically significant evidence of subsample instability. Significance levels of the tests of subsample stability range from .2 to .7

We now turn to estimation of the investment equation along the lines developed earlier.

Section III: Dividends as fundamentals

Our first step is to use dividends as a proxy for fundamentals. The rationale for this assumption comes from the work of Lintner (1956). From interviews with managers, Lintner concluded that dividends were largely set so as to be in line with permanent earnings as perceived by managers. The model of dividends has often been used since, for example recently by Marsh and Merton (1986) in their discussion of the work of Shiller. Using dividends rather than earnings as a measure of fundamentals has the additional virtue of avoiding issues relating to corporate liquidity constraints, at least as compared with using earnings.

The equation we estimate is (3) $\Delta \ln (I / K)-c+a(L) \Delta \ln (D / K)+b(L) \Delta \ln (V / D)+\epsilon$ 
Table 2. Investment, with dividends as fundamentals

\begin{tabular}{|c|c|c|c|c|c|c|}
\hline$\Delta \ln (I / K)$ & $\Delta \ln (D / K)$ & $\Delta \ln (D / K)(-1)$ & $\Delta \ln (V / D)$ & $\Delta \ln (V / D)(-1)$ & DW & $\mathrm{R}^{2}$ \\
\hline $\begin{array}{l}\text { Sample: } \\
\text { full }\end{array}$ & $\begin{array}{r}0.42 \\
(3.5)\end{array}$ & $\begin{array}{r}0.17 \\
(1.6)\end{array}$ & $\begin{array}{l}-0.02 \\
(-0.3)\end{array}$ & $\begin{array}{c}0.32 \\
(3.5)\end{array}$ & 1.61 & .39 \\
\hline prewar & $\begin{array}{r}0.56 \\
(2.8)\end{array}$ & $\begin{array}{r}0.14 \\
(0.9)\end{array}$ & $\begin{array}{r}0.05 \\
(0.4)\end{array}$ & $\begin{array}{r}0.23 \\
(1.3)\end{array}$ & 1.81 & .46 \\
\hline postwar & $\begin{array}{r}0.08 \\
(0.5)\end{array}$ & $\begin{array}{r}0.34 \\
(2.2)\end{array}$ & $\begin{array}{r}-0.11 \\
(-1.6)\end{array}$ & $\begin{array}{r}0.23 \\
(2.8)\end{array}$ & 1.87 & .26 \\
\hline
\end{tabular}

Significance levels of tests of the following hypotheses (full sample): set of coefficients on $D / K$ different from zero : $.4 \times 10^{-3}$

set of coefficients on $V / D$ different from zero : $.4 \times 10^{-2}$

sum of coefficients on $D / K$ and $V / D$ are equal : .15

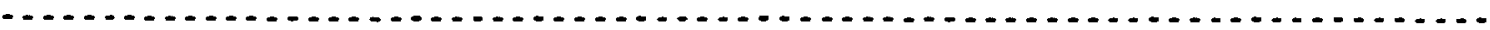

Full sample : 1902 to 1988; prewar : 1902-1939; postwar : 1948-1988

Table $2^{\prime}$. Investment, dividends and the dividend-price ratio

\begin{tabular}{|c|c|c|c|c|c|c|}
\hline$\Delta \ln (I / K)$ & $\Delta \ln (D / K)$ & $\Delta \ln (D / K)(-1)$ & $\Delta \ln (P D)$ & $\Delta \ln (P D)(-1)$ & DW & $\mathrm{R}^{2}$ \\
\hline $\begin{array}{l}\text { Sample: } \\
\text { full }\end{array}$ & $\begin{array}{r}0.47 \\
(4.1)\end{array}$ & $\begin{array}{r}0.12 \\
(1.2)\end{array}$ & $\begin{array}{r}-0.10 \\
(-1.2)\end{array}$ & $\begin{array}{r}0.32 \\
(3.5)\end{array}$ & 1.59 & .40 \\
\hline prewar & $\begin{array}{r}0.56 \\
(2.8)\end{array}$ & $\begin{array}{r}0.13 \\
(0.9)\end{array}$ & $\begin{array}{l}-0.00 \\
(0.4)\end{array}$ & $\begin{array}{r}0.27 \\
(1.3)\end{array}$ & 1.75 & .46 \\
\hline postwar & $\begin{array}{r}0.10 \\
(0.6)\end{array}$ & $\begin{array}{r}0.25 \\
(1.5)\end{array}$ & $\begin{array}{r}-0.10 \\
(-1.4)\end{array}$ & $\begin{array}{r}0.17 \\
(2.5)\end{array}$ & 1.94 & .23 \\
\hline
\end{tabular}

Full sample : 1902 to 1988 ; prewar : $1902-1939$; postwar : $1948-1988$ 
where first differences were imposed after finding that, when the equation was estimated allowing for an AR(1) disturbance term, the degree of serial correlation was not significantly different from one. Put simply, the equation asks to what extent movements in investment are related to movements in dividends or to movements in the dividend-price ratio (the reason why this is not quite right is that $V$ is not just the stock market value, but the sum of the values of both stocks and bonds; we return to this point below). The results are given in table 2, both for the whole sample, and for the prewar and postwar periods separately (we leave war years when using the whole sample, 1900-1988. Excluding them makes little difference). At most one $l a g$ on each variable is statistically significant.

The results are that both fundamentals, measured by dividends, and valuation matter. The sets of coefficients on fundamentals and valuation are both highly significant. The elasticity of investment with respect to dividends is equal to .59 for the whole sample, nearly twice the elasticity with respect to the market value given dividends of .32 . . But the sums of coefficients on fundamentals and the sum of coefficients on valuation are not significantly different: one can reject the hypothesis that investment responds to movements in $q$ independently of the source of the movements only at the 15 percent level. Results for prewar and postwar samples yield the same general conclusion.

Table 2' takes a brief detour from our basic argument. As we mentioned above, the regression reported in table 2 comes close to asking whether 
investment is more responsive to dividends or to the dividend-price ratio. It does not quite do that however, as it uses -appropriately under our assumptions- the total value of the firm rather than the stock market value. The results of regressions of investment on dividends and the dividend-price ratio (using the Standard and Poor index) are reported in table 2'. The specification is the same as in equation (3) except for the replacement of $(V / D)$ by the price-dividend ratio. While we cannot think of a structural interpretation for such a regression, we report it for two reasons. First, it requires much less data construction than regressions using market value, and thus may allow for easier cross country comparisons later. Second, a recent paper by Robert Barro (1989) has argued that ex post rates of return on stocks -roughly the first difference of the logarithm of the stock price-dominate changes in q in explaining changes in investment. The results of table 2' are easily summarized: they are nearly identical to those of table 2, both in terms of fit and individual coefficients. This may not be great news for $q$, but indicates that our findings are robust to the use of total market or stock market value.

Returning to our basic argument, there are two reasons why dividends may not be a good proxy for fundamentals. First, our underlying model of dividends may be wrong and dividends may not be set in line with permanent earnings as perceived by managers (after having constructed the ex post present discounted value of profits in the next section, we shall be in a position to test whether and how well dividends help predict this present discounted value, which they should if managers have rational expectations 
and set dividends in line with permanent earnings). Second, even if they are set in line with permanent earnings, dividends will not capture changes in the required rate of return which will affect fundamentals. Under the null hypothesis that only $q$ matters, then any decomposition of $q$ in the product of two terms does not matter and our estimates of the effects are consistent. But under the alternative hypothesis that the valuation term matters less than fundamentals or does not matter at all, those problems will likely lead to underestimating the effect of fundamentals relative to valuation ${ }^{5}$. This leads us to turn to an approach which, under the assumption of rational expectations, takes care of the first of those two problems.

Section IV. Investment and the present discounted value of profits

Our second step is to construct the expected present discounted value of profits and use it as our proxy for fundamentals.

More precisely, we first construct an ex-post present discounted value of the ratio of after tax profits to the capital stock. We construct it by

5 There is a third reason why dividends may not be a good proxy for fundamentals. We have disregarded the difference between marginal and average $q$, a difference which may well be empirically important. This case is however different from the other two. In the other two, the variable $(\mathrm{V} / \mathrm{K})$ is the appropriate one under the market perceptions hypothesis and only our decomposition is wrong. In this case, the variable $(V / K)$ is inappropriate even under the market perceptions hypothesis. As a result, our discussion of bias below does not apply to this case. Indeed, it is difficult in this case to predict even the sign of the bias of the coefficients on fundamentals and valuation. 


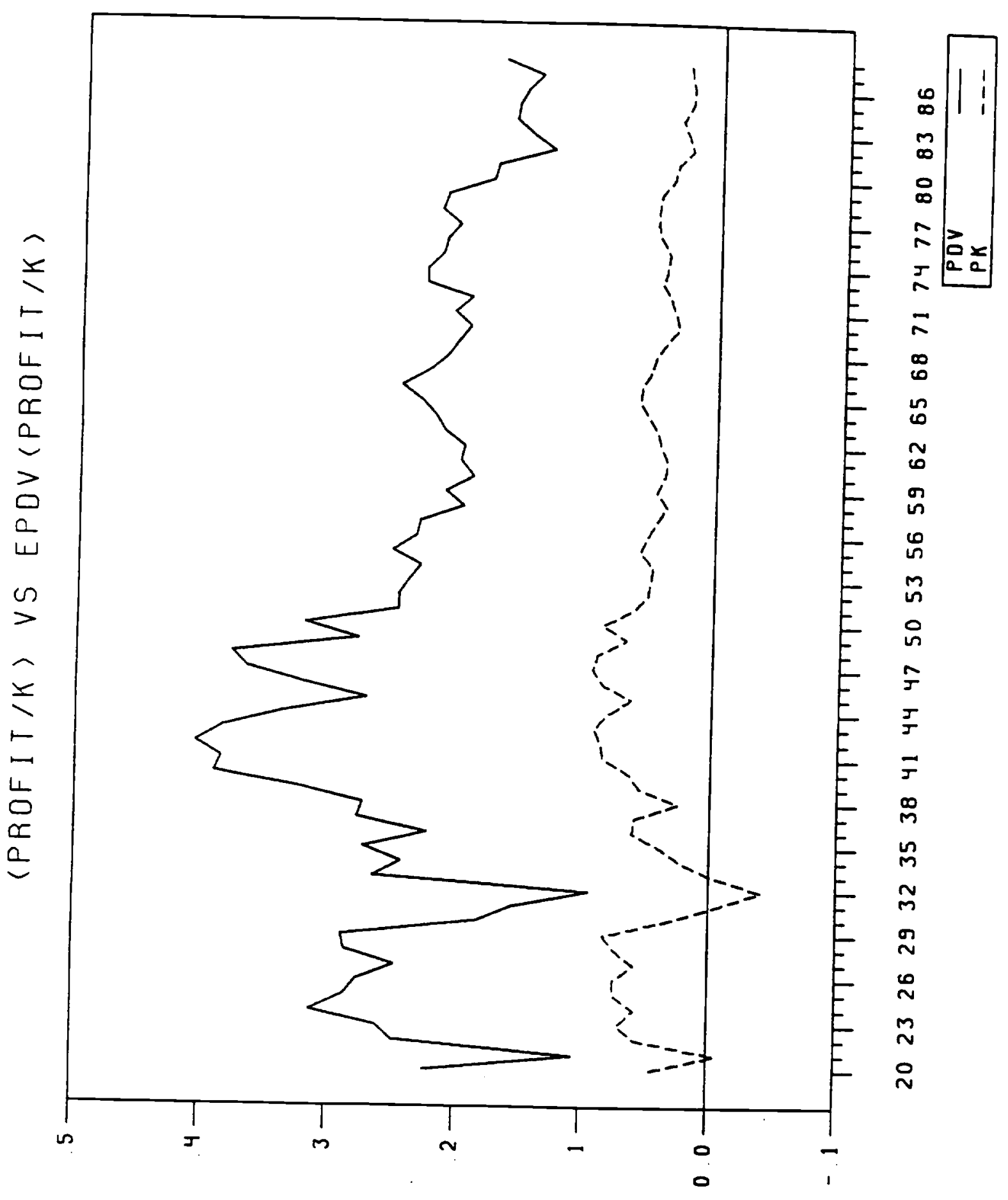


backward recursion, assuming that the ratio of profit to capital after 1988, our last observation, was expected to remain equal to its 1988 value. As we are trying to measure the present discounted value of profits accruing in the future to the current capital stock, we use a discount rate of 208, roughly the sum of the required rate of return and the depreciation rate. Varying the discount rate between 158 and 25 does not affect the results in an important way. We shall refer to the ex-post present discounted value as $P D V(\Pi / K)$, or PDV for short. Again as a descriptive statistic, the projection of the ex-post value on current and three lagged values of $q,(\Pi / K),(D / K)$ is plotted in figure 4 , together with $(\pi / K)$ itself. This projection can be thought of an estimate of the ex-ante present value.

The results of the regression used to construct the projected series are themselves of interest : $q$ has no predictive value, while the sets of coefficients on both $(\Pi / K)$ and $(D / K)$ are highly significant. The hypothesis that current dividends are a sufficient statistic for the present discounted value of profits, a hypothesis corresponding to the Marsh-Merton formalization of the Lintner hypothesis under rational expectations, is strongly rejected : current and lagged profits are strongly significant, even in the presence of current and lagged dividends.

We then estimate the following equation:

(4) $\Delta \ln (I / K)=c+a(L) \Delta \ln (P D V)+b(L) \Delta \ln (V / P D V)+\epsilon$

Because we use the ex-post present discounted value, the equation must be estimated by instrumental variables. As the equation is in first 
Table 3. Investment and the present discounted of profits.

$\Delta \ln (I / K) \quad \Delta \ln (P D V) \Delta \ln (P D V)(-1) \Delta \ln (V / P D V) \quad \Delta \ln (V / P D V)(-1){ }_{D W}{ }_{R^{2}}{ }^{2}$

Sample:

Full

$-0.07$

$(-0.3)$

0.62

(3.7)

0.07

$(0.5)$

0.30

$(2.6)$

1.86

.43

Prewar

$\begin{array}{lr}0.15 & 0.67 \\ (0.3) & (2.4)\end{array}$

0.10

(0.5)

0.32

(1.2)

2.38

.58

Postwar

$$
\begin{aligned}
& -0.39 \\
& (-1.3)
\end{aligned}
$$

0.56

(1.8)

0.00

$(0.0)$

0.27

(3.1)

$2.04 \quad .27$

Significance levels of tests of the fol set of coefficients on PDV/K different from zero: $.2 \times 10^{-3}-3$ full sample): set of coefficients on V/PDV different from zero: $.1 \times 10^{-1}$ sum of coefficients on $D / K$ and $V / D$ are equal $: .36$

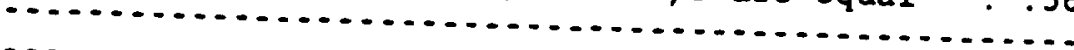

Full sample: 1918 to 1988 ; prewar: 1918-1939; postwar: 1948-1988 
differences, any variable in the information set at time $t \cdot l$ is a legitimate instrument: we thus use lagged values of $\ln (q), \ln (D / K)$ and of $\Pi / K$, with one to three lags. Note that we use the level rather than the logarithm of $\pi / K$ : this is because the value of $\pi / K$ is negative in 1921 and in 1931-1933. This is not an issue for the ex-post PDV variable which is always positive in the sample, so that we can take its logarithm in equation (4).

The results are presented in table 3, for the whole sample as well as for the pre- and post-war subsamples (standard deviations are adjusted to take account of the structure of the residual). The image they give is surprisingly similar to that given in table 2. Both fundamentals and valuation matter: the set of coefficients on each is highly significant. Point estimates of the effects of fundamentals are larger (.55 for the whole sample) than those of the effects of valuation (.37 for the whole sample), but the difference between the two effects is still not significant. A surprising feature is the negative effect in the full and the postwar samples of the current present discounted value, which however is insignificant and smaller in absolute value than the positive effect of the lagged present value. This negative coefficient becomes larger (while the sum of coefficients remains roughly unchanged) as the discount rate used to compute the present discounted value becomes smaller.

This second set of results is very much dependent on the assumption of rational expectations. It is also subject to the other problem we mentioned at the end of the previous section, time varying discount rates. 
In the next section, we focus on the nature and the potential size of the bias inherent in our approach.

\section{Section $V$. Proxies for fundamentals and bias.}

Using the dividend -or any other observable variable- as a proxy for fundamentals implies treating all movements in the dividend-price as containing no information about fundamentals. This is surely wrong, and leads to systematic bias. What is the nature and the potential size of the bias? As usual, the answer depends on unobservable variables, but some progress can be nevertheless be made.

Suppose that the true model is given by:

(5) $\Delta \ln (I / K)=a \Delta \ln (F / K)+b \Delta \ln (V / F)+\eta$

Compared to the equation which underlies estimation in the previous sections, equation (5) makes two simplifications which will simplify the algebra. It ignores the constant term, and assumes away the lags. Assume further, and again only to simplify the algebra, that all terms are white noise, an assumption which is roughly true of their empirical counterparts.

Now suppose that we use a proxy $X$ for fundamentals, and estimate instead:

$$
\Delta \ln (I / K)-\alpha \Delta \ln (X / K)+\beta \Delta \ln (V / X)+\eta^{\prime}
$$

The question is then that of the bias in $\alpha$ and $\beta$. The answer depends on the correlation structure between $F, X$ and $V$. The arguments above suggest that the main issue is that a proxy such as dividends will only capture only part of fundamentals, suggesting the following correlation structure:

Assume that fundamentals have two components, only one being captured by $X$, so that: 
$\Delta \ln (F / K)-\Delta \ln (X / K)+c$

where $c$ is that component of the change in fundamentals not captured by $x$. In the absence of good reasons to the contrary, assume further that the two components of fundamentals are mutually uncorrelated, and that each is uncorrelated with the valuation term:

$$
\rho(\Delta \ln (X / K), \epsilon)-\rho(\Delta \ln (V / F), \Delta \ln (X / K))-\rho(\Delta \ln (V / F), \epsilon)=0
$$

Finally define $x \in[0,1]$ as the proportion of the change in the measured valuation term due to fundamentals (for example, when we use dividends, the proportion of the change in the dividend price ratio due to changes in fundamentals):

$$
x=\operatorname{Var}(\epsilon) /(\operatorname{Var}(\epsilon)+\operatorname{Var}(\Delta \ln (V / F))
$$

Simple algebra then yields the following formulas:

$$
E(\alpha)=a ; E(\beta)-x a+(1-x) b ; E(\alpha-\beta)-(1-x)(a-b)
$$

Thus, under the market perceptions hypothesis that amb, misallocating part of the fundamentals in the valuation term does not lead to bias. But under the alternative hypothesis that fundamentals matter more than valuation, this misallocation will lead to an upward bias on the valuation term, thus to a downward bias on the difference between $a$ and $b$. Take for example the results of table 2 , which uses dividends as a proxy for fundamentals. Taking $\alpha$ and $\beta$ to be equal to the sum of coefficients on $(D / K)$ and $(V / D)$ respectively, yields $\alpha-.59, \beta-.30$, and thus $\alpha-\beta-.29$. Suppose that half of the change in the dividend price ratio is due to fundamentals, half to true valuation effects, bubbles, fads and the like. Then, the above formula suggests that the positive value of $\beta$ is due to bias, that the true value of $b$ is in fact equal to zero. 
Thus, while we wish it were otherwise, the conclusions one reaches depend on one's initial prior.

Suppose that one believed that there were no fads or bubbles, that the market value always reflected fundamentals, and that the whole estimation exercise was useless. One would then expect that dividing $V / K$ in two arbitrary components should lead to identical point estimates on each of the two components. The evidence is that point estimates are different but not significantly so. Thus the prior would be little affected by the evidence.

Suppose that one believed instead that there were fads or bubbles, and that the market perceptions hypothesis were true. Then, estimated coefficients would be unbiased estimates of true parameters, and again, the evidence would not affect that prior very much.

Suppose finally that one belleved that there were fads or bubbles, that the managerial perceptions hypothesis were true, and that the constructed valuation term contained information about fundamentals. Then, one could interpret the results as strongly supporting the hypothesis. It is our prefered interpretation, but we realize that it is only one of three.

In our last section, hoping for stronger evidence, we focus on particular episodes rather than on general time series evidence. 
Looking at residuals

The rationale for our last set of regressions is straightforward and relies on a standard errors-in-variables argument. Suppose that the managerial perceptions hypothesis is correct, that managers react to fundamentals and ignore valuation. Then $q$ will be a proxy for fundamentals, and its quality will depend on the size of the valuation term. In times when the valuation term is large, investment will respond less to $q$ than would be predicted by a regression of investment on $q$, leading to a specific pattern of residuals.

Again, the valuation term is unobservable. But there are at least two episodes during which there is widespread suspicion that increases in the stock market were not primarily reflecting fundamentals, but also had an important bubble component ${ }^{6}$.

The first is the increase in the stock market leading to the crash of October 24, 1929. While there was was an increase in the stock market in every year from 1922 on, the increase accelerated in 1928 and 1929 and it is at that time that market analysts started referring to the possibility of a bubble. Table 4 gives the behavior of the Cowles Commission index for the period. The increase was associated with steady increases in the

\footnotetext{
6
}

A literature survey of magazines during 1929 turned up a number of such statements. For example, on september 7, 1929, Business week warned : "... are generally out of has eaten nearly all of its credit cake. Stock prices is now almost wholly "psycholo safe earnings expectations, and the market apprehensive of the "psychological" -irregular, unsteady, and properly

But for one the inevitable readjustment which draws near..." mock an unfounded auote, one can find in the same magazine others which crash, many thought of the increase as unrealistically low level of thease as a "catching up" effect from the 


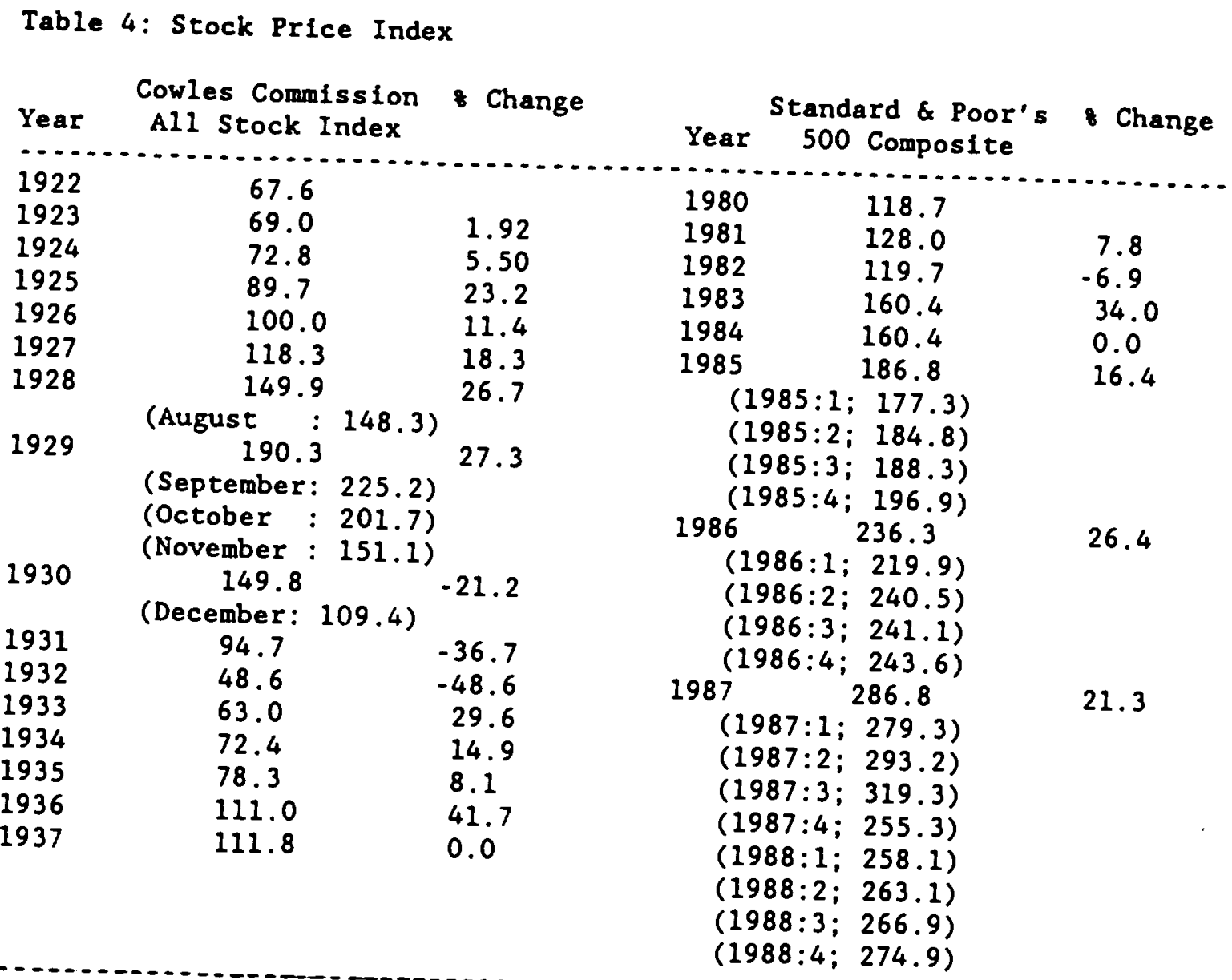

1. Figures are annual or quarterly averages. 
price-earnings ratio and steady decreases in the dividend price ratio. The PE ratio, which stood at 10.9 at the end of 1926, had increased to 17.6 at the end of 1928, decreasing to 13.3 at the end of 1929, after the crash. The dividend price ratio, which stood at 5.1 at the end of 1926 had decreased to 3.5 at the end of 1928 , increasing to 4.5 after the crash.

The second is the increase in the stock market leading to the crash of October 19, 1987. The stock market increased from 1984 on, accelerating in 1987, triggering talk of speculative bubbles during that year. Table 4 gives the behavior of the S\&P index for the period. Again, the episode was associated with sharp increases in the $\mathrm{PE}$ ratio, sharp decreases in the dividend price ratio. The PE ratio increased from 11 at the end of 1984 to 20.3 in the third quarter of 1987 , decreasing to 14.0 at the end of 1987 , after the crash. The dividend price ratio decreased from 4.8 at the end of 1984 to 2.7 in the third quarter of 1987 , increasing to 3.5 at the end of 1987.

To the extent that the managerial perceptions hypothesis is correct, that managers were not responding, or not responding fully, to the increase, one would expect - in a regression of the rate of change of investment on the rate of change in $q$ - negative residuals in the years leading to 1929, and positive residuals as the market declined from 1929 to 1932, negative residuals in the years leading to 1987, and positive residuals in 1988.

The regression we run is therefore:

$$
\Delta \ln (I / K)-c+a(L) \Delta \ln (q)+\epsilon
$$

We run it both for the whole sample and separately for each of the prewar and postwar subsamples. The regressions and the residuals for 1925.1935 
Table 5. Investment and $q$

Dependent variable : $\Delta \ln (I / K)$

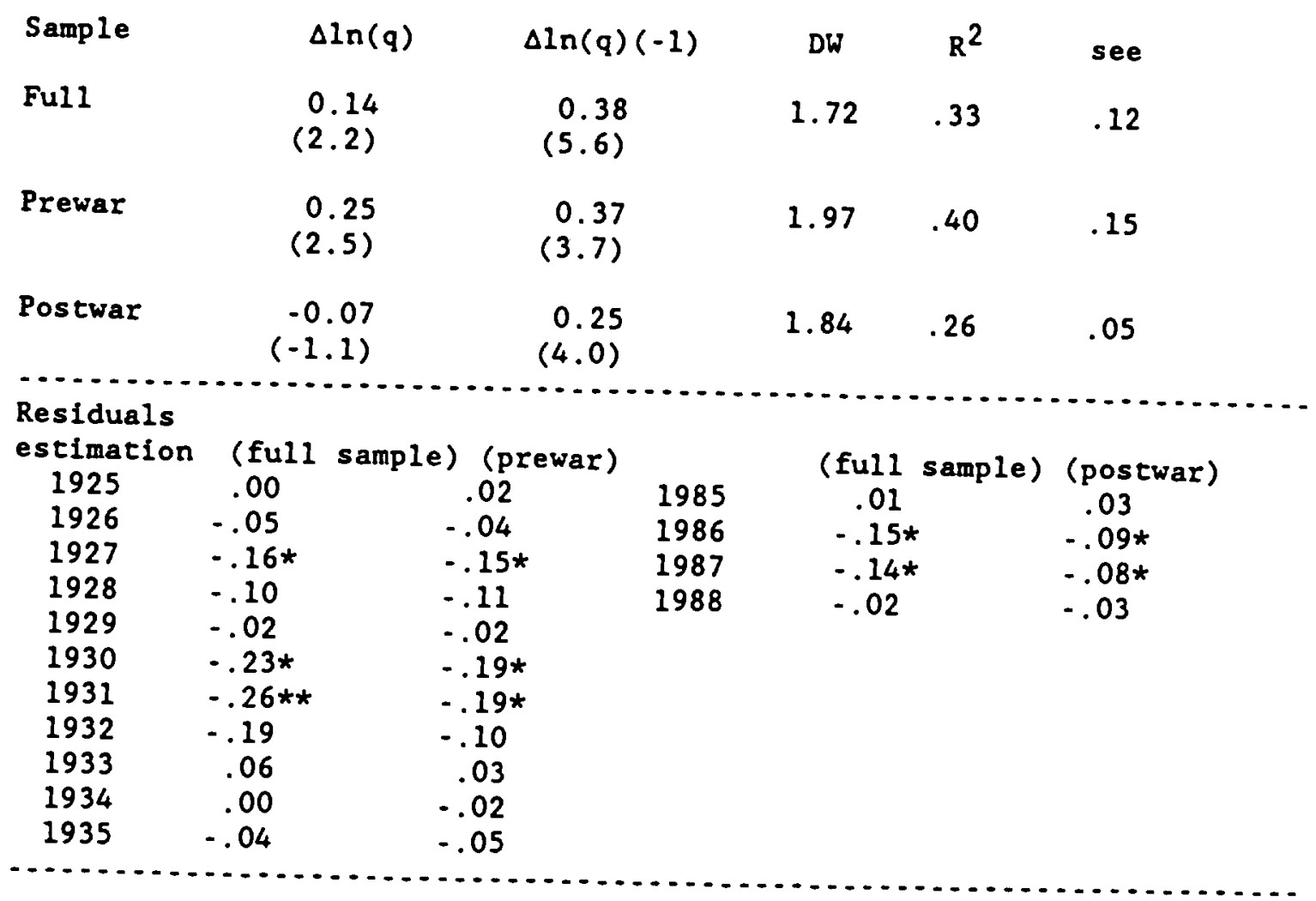


and for 1985-1988, from full and subsample estimation are given in table 5. The results of the regressions are very similar to those of table 1, which were run in first differences of levels rather than of logarithms. The regressions show a strong effect of lagged $q$, a weak effect of current $q$ (actually negative but insignificant in the postwar sample). This implies that the timing of residuals we just discussed may be off by a year. Because investment responds in part to last year $q$, the regression may still underpredict investment even in the year after the crash. With this in mind, we look at the two sequences of residuals.

Residuals are consistently negative from 1926 to 1932, with the largest residuals occuring in 1930-1932. The 1926-1930 period nicely fits the hypothesis that there was a bubble, and that it was largely ignored by managers. But the negative residusls in 1931-32 do not fit what one would have expected under that hypothesis. Perhaps, the serious credit problems of the early 30's are to blame; perhaps, fundamentals declined after the crash even more than the market allowed for. And most of the decline in the real value of the market occured not in 1929 but between 1930 and 1932 . Nevertheless, it is fair to say that the residuals do not fit any of our simple hypotheses.

The managerial perceptions hypothesis fares better during 1986-1988. The residuals are large and negative in both 1986 and 1987 (one must go back to 1958 to find a larger residual in the full sample regression). The residual from 1988 is still negative, but this is easily explained by the fact, reflected in the regression, that investment spending in 1988 was still largely the result of decisions taken before october 1987 . (We have 
not yet been able to construct the value of $q$ for 1989, which would clearly be of interest here).

We have checked whether the behavior of investment in 1987 and after could be explained by the tax reform of 1986 and the change in the relation between marginal and average $q$ it introduced. To do so we constructed two tax-adjusted $q$ series for the postwar period; the two series are based on different assumptions about the effects of dividend taxation (see Poterba and Summers (1985)). The residuals from regressions using those tax adjusted $q$ were similar to those in table 5 .

Financing and investment.

In section $I$, we argued that if managers were going to respond to market valuation even when it exceeded their assessment of fundamentals, they were likely to do this by issuing new shares as this is the simplest way of effecting a transfer from new to existing shareholders. Thus, table 6 looks at the composition of investment finance for both the 1929 and 1987 periods.

The evidence from the table is clear cut for each of the two episodes, but the two episodes yield opposite conclusions. Net issues of stock were indeed unusually large for 1928 and 1929, with net issues of stocks being nearly as large as retained earnings as a source of finance in 1929 . This can be taken as evidence that managers thought their shares were overvalued in the late 1920s. and as evidence in favor of the market perceptions hypothesis. The evidence from the 1987 goes mostly the other way. Since 1984, net issues of stock have been strongly negative, reflecting the 
Table 6. Proportions of Total Financing by Particular Sources of Funds.

\begin{tabular}{|c|c|c|c|c|c|}
\hline year & $\begin{array}{c}\text { capital } \\
\text { expenditures }\end{array}$ & $\begin{array}{l}\text { retained } \\
\text { earnings }\end{array}$ & $\begin{array}{l}\text { Net issues } \\
\text { of stock }\end{array}$ & $\begin{array}{l}\text { Net issues } \\
\text { of cor. bond }\end{array}$ & $\begin{array}{c}\text { common } \\
\text { stock issues }\end{array}$ \\
\hline $\begin{array}{l}1925 \\
1926 \\
1927 \\
1928 \\
1929 \\
1930 \\
1931\end{array}$ & $\begin{array}{r}8.72 \\
8.69 \\
7.93 \\
7.93 \\
10.06 \\
3.95 \\
0.88\end{array}$ & 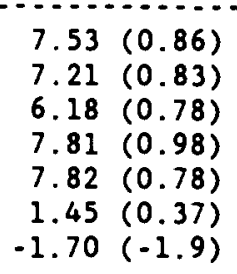 & $\begin{array}{l}2.30(0.26) \\
1.84(0.21) \\
2.26(0.28) \\
4.34(0.55) \\
7.48(0.74) \\
1.91(0.48) \\
0.61\end{array}$ & $\begin{array}{l}2.79(0.32) \\
3.03(0.35) \\
3.55(0.45) \\
2.45(0.31) \\
0.66(0.07) \\
1.95(0.49) \\
0.22(0.25)\end{array}$ & $\begin{array}{l}0.61 \\
0.67 \\
0.68 \\
2.09 \\
5.06 \\
1.10 \\
0.19\end{array}$ \\
\hline $\begin{array}{l}1980 \\
1981 \\
1982 \\
1983 \\
1984 \\
1985 \\
1986 \\
1987\end{array}$ & $\begin{array}{l}243.7 \\
286.5 \\
256.4 \\
270.6 \\
370.6 \\
342.3 \\
331.4 \\
361.3\end{array}$ & $\begin{array}{ll}200.1 & (0.82) \\
239.4 & (0.83) \\
242.3 & (0.94) \\
285.6 & (1.06) \\
336.2 & (0.90) \\
352.2 & (1.02) \\
357.4 & (1.08) \\
352.7 & (0.98)\end{array}$ & $\begin{array}{r}12.8(0.05) \\
-11.4(-.03) \\
6.4(0.02) \\
23.5(0.09) \\
-74.4(-.20) \\
-81.5(-.23) \\
-80.7(-.24) \\
-76.5(-.21)\end{array}$ & $\begin{array}{r}27.6(0.11) \\
22.7(0.08) \\
18.6(0.07) \\
16.0(1.06) \\
46.1(0.12) \\
73.7(0.21) \\
121.2(0.36) \\
99.9(0.28)\end{array}$ & $\begin{array}{r}12.67 \\
14.23 \\
13.40 \\
29.79 \\
8.66 \\
18.38 \\
33.73 \\
37.67\end{array}$ \\
\hline
\end{tabular}

1. Figures are in billions of dollars. Figures in parentheses are ratios to capital expenditures. Capital expenditures include fixed investment, change of inventories and inventory valuation adjustment. Retained earnings include capital consumption

allowances. Net issues of stock include preferred stock as well as common stock. 2. Data before 1931 were constructed following table B-19 in Goldsmith (1956). These data include financial institutions, whereas data for 1980 and after refer to non financial corporations, except for the last column.

4. In the last column, the data before 1931 is serles 515 in Historical statistics of the U.S. (1975). The data after 1980 are gross proceeds from primary public offerings of conventional common stock in the various issues of Monthly Statistical Review, U.S. Securities and Exchange Commission. The two series are different in many respects, as explained in $p 998$ in Historical Statistics of the U.S. (1975). Moreover, the data before 1931 is different from Goldsmith's on which the third colum of the table is based. Goldsmith estimated net issues of stock from individuals' saving through common and preferred stock. 
increase in share repurchases, takeovers, mergers and acquisitions.

Obviously, these developments have other sources than the decisions we are focusing on ${ }^{7}$; there is however no evidence that net repurchases of stock slowed down in 1986 or $1987^{8}$

Thus, the evidence from the 1929 episode is mixed. Investment behavior points, with a few puzzles, in the direction of managers largely ignoring the market, but the evidence on issues of new shares points the other way. In the 1987, both financing and investment behavior point support the idea that managers largely ignored market developments.

\section{Conclusion}

We have already admitted to having started this paper with a prior, that managers probably largely ignored market valuation whenever that valuation differed from their perceptions of fundamentals. We see the evidence as consistent with that prior. But we also have to admit that the evidence is not strong enough to sway those with different priors. Somebody who believed either that there were simply no fads or bubbles, or that firms followed market valuation would hold roughly the same views after reviewing the evidence we have presented.

This general conclusion is shared by two other recent papers, Barro (1989), and Galeotti and Schiantarelli (1989). Barro uses a related

7 Historically, mergers and acquisitions have happened in periods of high stock prices and high values of $q$ (Golbe and White 1988).

The evidence on gross issues of stocks does not show any clear pattern. Gross issues were equal to $52 \mathrm{~b} \$$ and $57 \$$ in 1987 and 1986, up from the ir values in 1984-5, but roughly the same as in 1983 (Securities Industry Yearbook, varlous issues) 
approach and also looks at long time series for the US. One of his findings is that the ex-post rate of return on the stock market dominates the rate of change of $q$ (Barro uses our $q$ series). We find it interesting, but have no ready explanation. Galeotti and Schiantarelli use our post war quarterly data and a more formal, Euler equation, approach; they find no evidence against the hypothesis that fads affect investment.

Reaching clearer conclusions will therefore require either superior procedures for separating fundamentals and valuation errors, or bringing more information to bear on the problem. This could be done by using either international data or information on individual firms. 
Appendix I: Data Sources for the Construction of $q$.

We have constructed two series for $q$. The first is an annual series for the period 1900-1958. The other is a quarterly series for the perlod 19521988. The annual series for 1900 to 1988 used in the regressions is composed of the annual series from 1900 to 1951, and the annual series from time aggregation of the quarterly series thereafter.

The series were constructed as follows:

1> Market Value of Equity

The market value of equity of non-financial corporations was estimated by dividing dividend payments by the common-stock dividend-price ratio.

a) Dividends paid by non-financial corporations.

1) For annual q: From 1922 to 1958, dividend payments by "all active corporations" were retrieved from various issues of Statistics of Income. Dividends paid by finance, real estate, and the related business sectors were subtracted to get dividends from non-financial corporations. The real estate sector was excluded since it could not be separated from the other two before 1937. For the period from 1900 and 1922, the data came from table c-31 and c-6 in Studies of Saving in the United States, Vol I (1955). In those tables, dividends from the banking sector (instead of the total finance sector) are listed from 1900 to 1915. Financial corporations' dividends were estimated by multiplying dividends from the banking sector by 1.6 under the assumption that the banking sector accounted for almost 60 
per cent of the whole finance sector during this period. This assumption is derived from the table 12 in Financial Intermediaries in the American Economy Since 1900 (1958).

2) For quarterly $q$ : This paper used dividend payments data from the DRI Flow of Funds data bank. Because of the recent NIPA data revision, which has reduced the value of dividends paid, $q$ in this paper is smaller than $q$ found in Furstenberg (1977) by roughly 0.1 , even though both series are constructed in the same way.

b> Dividend price ratio:

1) For annual q: Before 1930, the Cowles Commission common stock yields were used. After 1930, Moody's common stock yields ratio series were used (series $\times 479$ and $\times 483$ in Historical Statistics of the U.S. (1975)).

2) For quarterly q: Standard and Poor's 500 common stock yields ratio was used.

2> Market Values of Debt and Non-Interest-Bearing Assets.

1) For annual $q$ : Studies of Saving in the United States, Vol III (1955), presents balance sheets of non-financial corporations for the years 1900 , 1912, 1922, 1929, 1933, 1939, and 1945-1958. Short term debt was netted out from non-interest-bearing assets (e.g., cash, consumer credit, accounts receivable,..) to calculate the book value of net non-interest-bearing assets. This book value in turn was assumed to be the same as their market value. Likewise, interest-bearing assets were netted out from the counterparts in the liability side to calculate net long-term debt. Using 
linear extrapolation, the book value of net long-term debt in each year was calculated. This book value was converted into a market value using the series $\times 494$ in Historical Statistics of the U.S. (1975): It amounts to using Moody's corporate Aar bond yleld rate assuming a 20-year maturity for conversion.

2) For quarterly q: The same method as in Furstenberg (1977) was adopted: First, net non-interest-bearing assets, net long-term debt and net shortterm debt were calculated. Second, the market value of short-term debt was assumed to be the same as its book value. The book value of net long-term debt was converted to the market value by capitalizing net interest payment figures by the yield rate on Moody's corporate $A$ bond. The equation (1) in Von Furstenberg (1977, p357) was used for conversion, assuming a ten year maturity. All the data came from the DRI Flow of Funds data base.

3) Replacement Cost of Tangible Assets

1) For annual q: Studies of Saving in the U.S., Vol III (1955), presents the replacement cost of total tangible assets in the U.S. from 1900 to 1958. By using the sectoral balance sheets (available for the 20 years listed previously), the proportion of non-financial corporations' tangible assets to total tangible assets was extrapolated for the years in which the balance sheets are not available. The ratios so calculated ranged between 0.238 in 1900 and 0.287 in 1929 . By multiplying this proportion to the replacement cost of tangible assets in the U.S., the nonfinancial corporations' tangible assets were calculated.

2) For quarterly q: Data came from the DRI Flow of Funds data bank. 
4> Calculation of $q$

$q$ is defined as ( Market value of equity + market value of debt - non interest bearing assets)/Replacement cost of tangible asset. Note that non-interest-bearing assets were subtracted from the numerator. This differs from Von Furstenberg's method, which added them to the denominator instead.

5) Investment.

The annual data on investment by non-financial corporations on equipment and structure (from 1832 to 1987) were obtained from the BEA wealth tape. The seasonally adjusted quarterly data after 1952 came from the DRI Flow of Funds data bank. 
The serles for annual $q$ is :

\begin{tabular}{|c|c|c|c|}
\hline 0 & .607220 & & \\
\hline 1 & .811250 & 45 & .656740 \\
\hline 2 & 1.23872 & 46 & .770330 \\
\hline 3 & .986740 & 47 & .581990 \\
\hline 4 & 1.08545 & 48 & .525210 \\
\hline 5 & 1.28335 & 49 & .438690 \\
\hline 6 & 1.18924 & 50 & .495670 \\
\hline 7 & .904690 & 51 & .465040 \\
\hline 8 & .925040 & 52 & .483230 \\
\hline 9 & 1.05977 & 53 & .468880 \\
\hline 10 & 1.03116 & 54 & .528570 \\
\hline 11 & .973690 & 55 & .650610 \\
\hline 12 & .987720 & 56 & .637060 \\
\hline 13 & .980030 & 57 & .575100 \\
\hline 14 & .790920 & 58 & .604340 \\
\hline 15 & .808830 & 59 & .733930 \\
\hline 16 & .775130 & 60 & .708850 \\
\hline 17 & .538430 & 61 & .796050 \\
\hline 18 & 396000 & 62 & .752090 \\
\hline 19 & .393370 & 63 & .846550 \\
\hline 20 & .389820 & 64 & .915430 \\
\hline 21 & .356480 & 65 & .995050 \\
\hline 22 & .462910 & 66 & .902700 \\
\hline 23 & .503410 & 67 & .924860 \\
\hline 24 & .495310 & 68 & .965870 \\
\hline 25 & .631000 & 69 & .868950 \\
\hline 26 & .679470 & 70 & .704350 \\
\hline 27 & .787210 & 71 & .769610 \\
\hline 28 & .980880 & 72 & .829420 \\
\hline 29 & 1.25887 & 73 & .761610 \\
\hline 30 & 1.11039 & 74 & .513340 \\
\hline 31 & .707600 & 75 & .473150 \\
\hline 32 & .357290 & 76 & .509780 \\
\hline 33 & .568460 & 77 & .460330 \\
\hline 34 & .905330 & 78 & .418420 \\
\hline 35 & 1.16509 & 79 & .375690 \\
\hline 36 & 1.28278 & 80 & .385670 \\
\hline 37 & 1.15208 & 81 & .396340 \\
\hline 38 & .890620 & 82 & .392380 \\
\hline 39 & 1.08110 & 83 & .523530 \\
\hline 40 & .823090 & 84 & .524690 \\
\hline 41 & .672990 & 85 & .582360 \\
\hline 42 & .508620 & 86 & .720460 \\
\hline 43 & .642890 & 87 & .839250 \\
\hline 44 & .632300 & 88 & .742040 \\
\hline
\end{tabular}




\section{Bibliography}

Abel, A.B. and O.J. Blanchard (1986), "The Present Value of Profits and Cyclical Movements in investment," Econometrica, 54-2, pp. 249-272

Barro, R., (1989) "The Stock Market and Investment", mimeo Harvard

Blanchard, O.J. and M. Watson (1982), "Bubbles, Rational Expectations and Financial Markets, " in Crises in the Economic and Financial Structure, ed. by $P$. Wachtel. Lexington, Mass., Lexington Books.

Brainard, W., J. Shoven, and L. Welss (1980), "The Financial Valuation of the Return to Capital," Brookings Papers on Economic Activity 2: p453-511.

Bosworth, B. (1975), "The Stock Market and the Economy, "Brookings Papers on Economic Activity 2: p257-300.

Delong, J.B., A. Shleifer, L.H. Summers, and R.J. Waldmann (1987), "Noise Trader Risk in Financial Markets," National Bureau of Economic Research Working Paper No. 2395.

Fazzari, S., R. Hubbard, and B. Petersen (1988), "Financing Constraints and Corporate Investment," Brookings Papers on Economic Activity, 1988:1, p141206.

Fischer, S. and R.C. Merton (1984), "Macroeconomics and Finance: The Role of The Stock Market, "Carnegie-Rochester Conference Series on Public Policy 21, p57-108.

Galeott1, M. and F. Schiantarelli (1989), "Stock Market Volatility and Investment: Do Only Fundamentals Matter?, "mimeo, Boston University.

Golbe, D.L. and L.J. White (1988), "Mergers and Acquisitions in the U.S. Economy: An Aggregate and Historical Overview, " in Mergers and Acquisitions, ed. by A.J. Auerbach, Chicago: The University of Chicago Press.

Goldsmith, R.W. (1956), A Study of Saving in the United States, 3 vols. Princeton: Princeton University Press. (1958), Financial Intermediaries in the American Economy Since 1900, Princeton: Princeton University Press.

Hayashi, F. (1982), Tobin's Marginal Q and Average Q: A Neoclassical Interpretation, Econometrica 50: p213-224.

Hosh1, T, A. Kashyap, and D. Scharfstein, (1988) "Corporate Structure and Investment: Evidence from Japanese Panel Data," mimeo, M.I.T.

Jorgenson, D.W. and K.Y. Yun (1986), "Tax Policy and Capital Allocation," The Scandinavian Journal of Economics 88(2), p355-377. 
Keynes, J.M. (1936), The General Theory of Employment, Interest and Money, London: MacMillan.

LeRoy, S., and R. Porter (1981), "The Present Value Relation: Tests Based on Implied Variance Bounds," Econometrica, May, p555-574.

Lintner, J.V. (1956), "Distribution of Incomes of Corporations Among Dividends, Retained Earnings, and Taxes," American Economic Review Proceedings, May, p97-118.

Marsh, T.A. and R.C. Merton (1986), "Dividend Variability and Variance Bounds Tests for the Rationality of Stock Market Prices," American Economic Review, June, p483-503.

Myers, S. and N. Majluf, "Corporate Financing and Investment Decisions when Firms have Information that Investors do not Have", Journal of Financial Economics, 1984, 187-221

Poterba, J.M. and L.H. Summers (1985), "The Economic Effects of Dividend Taxation" in (Altman and Subramaynan ed.) Recent Developments in Corporate Finance.

Summers, L.H. (1981), "Taxation and Corporate Investment: A Q Theory Approach," Brookings Papers on Economic Activity 1, p67-140.

Tobin, J. and W.R. Brainard (1977), "Asset Prices and the Cost of Capital," Economic Progress, Private Value, and Public Policy, ed. by Bela Balassa and Richard Nelson, New York: North Holland.

Von Furstenberg, G.M. (1977), "Corporate Investment: Does Market Valuation Matter in the Aggregate?," Brookings Papers on Economic Activity 2: p347407. 
</ref_section> 